\title{
Apparent combined length of two-line and four-line sets ${ }^{1}$
}

\author{
LESTER E. KRUEGER ${ }^{2}$ \\ HAR VARD UNIVERSITY
}

\begin{abstract}
Recent studies, using single-line stimuli, show apparent length to be a power function, with exponent 1.0, of objective or physical length. If apparent lengths are additive, then, given the 1.0 exponent, two lines should appear to $S$ to have the same total length as the single line they would form if physically joined. When $S$ adjusted the length of one line to match the combined length of two other lines, however, he generally made the variable line much longer than the actual combined length of the two lines. Dividing the total length equally between the two lines, so that each had 50\%, represents the greatest departure from a single line, yet the largest overestimation occurred when one of the two lines had $65 \%$ to $75 \%$ of the total length. The overestimation was greater when the lines were spaced farther apart, suggesting that the amount of area occupied by the lines affected apparent combined length.
\end{abstract}

A central concern in perception, particularly for the Gestalt school, is the way in which $S$ organizes and combines proximate sensory elements into a unitary percept. One aspect of the unitary percept is its apparent magnitude. The present study measures how apparent combined length changes as a single line is split into two or four line segments.

Line length was chosen for study because it is so simple a stimulus dimension and can be so accurately judged, possibly because there are innate "operators" that organize certain retinal arrays into lines, like those found in frogs and cats (Lettvin, Maturana, Pitts, \& McCulloch, 1961; Hubel \& Wiesel, 1962). Recent studies have shown apparent length of single lines to be a power function of objective or physical length, with an exponent of about 1.0 (e.g., Stevens, 1957; Stevens \& Galanter, 1957; Stevens \& Guirao, 1963; Teghtsoonian, 1965; Teghtsoonian \& Teghtsoonian, 1965). That is, $\mathrm{R}=\mathrm{kS}^{1.0}$, where $R$ is apparent length, $S$ is objective length, and $k$ is a constant. Thus "apparent length is very nearly a linear function of physical length [Stevens \& Galanter, 1957, pp. 378-379]," and "a line that is twice as long as another looks about twice as long [Stevens \& Guirao, 1963, p. 179] ."

In the present study, where $S$ must judge the combined length of two or four lines, however, will additivity hold, such that the apparent combined length for the two or four lines equals the sum of the apparent length for the two or four lines rated separately? That is, given the exponent of 1.0 , will several adjacent line segments look equal in combined length to the single line that they would form when physically combined? When Goude (1962) had S lift three items in succession and then tell whether the first two seemed to weigh more or less in toto than the third, the subjective or apparent combined weight of the two proved greater than the sum of their individual apparent weights. When Goude had $S$ adjust the size of one angle to equal the sum of two other angles (method of sum production), however, he found that the apparent combined angle was predicted quite well by the sum of the apparent magnitudes of the individual angles. Dawson (1968) employed difference production rather than sum production, having $S$ adjust a third stimulus to equal the magnitude that would result from the subtraction of one stimulus from a (larger) second stimulus. To a slight extent on apparent area and a considerable extent on loudness, the third stimulus was set too low, relative to the difference predicted by subtracting the apparent magnitude of the first stimulus (rated separately) from that of the second.

\section{EXPERIMENTS 1 TO 4}

Experiment 1 used one-line (control) and two-line test stimuli, with the distribution of objective length between the two lines varying in $5 \%$ steps between 5/95 (i.e., $5 \%$ to top line, $95 \%$ to bottom line) and 50/50. Experiment 2 used four-line as well as one- and two-line test stimuli, but tested fewer steps on the distribution-of-length range. Experiment 3 was the same as Experiment 2, except that the lines were strung out horizontally, rather than stacked one on top of the other. Experiment 4 varied the spacing between lines, with some sets stacked closer together than others.

\section{Method}

Apparatus and procedure. S sat about $2 \mathrm{ft}$ (no chin or head restraint was used) from a $1 \times 6 \mathrm{ft}$ board slanted $30 \mathrm{deg}$ from horizontal towards $\mathrm{S}$. On each trial, the test stimulus, centered on a $9 \times 24$ in. sheet, was placed on the left side of the board. In the center of the board was a long comparison line whose length could be adjusted by $S$ to match the combined length of the one, two, or four lines constituting the test stimulus (method of sum production). All lines (comparison and test) were drawn in black with a No. 1 Rapidograph pen and were about $.02 \mathrm{in}$. thick. Out of sight from $S$, a ruler on the far right side of the board revealed how long $\mathrm{S}$ had made the comparison line.

$S$ was encouraged to move the cover on the comparison line back and forth to obtain the best possible match. $S$ was told to adopt a global perceptual set and to judge how long the two or four lines looked as a whole, without mentally rearranging them or mentally summing their individual lengths. After each match, $E$ recorded the length of the comparison line and then reset it to zero length. The several lines to be perceptually combined were presented simultaneously rather than successively (cf. Goude's study on weight), because showing one line at a time would have encouraged an analytical attitude.

Test stimuli. In Experiment 1, each $S$ saw 33 one- and two-line stimuli, one after the other, in a different order which was random except that no two successive stimuli had the same objective combined length. The objective combined lengths were $1.5,3.0$, and $6.0 \mathrm{in}$. for 11 test stimuli each. Within each set of 11 , the percent distribution of objective length between the two lines was varied in $5 \%$ steps: 0/100 (i.e., a single line, included as a control), 5/95, 10/90, .., 45/55, and $50 / 50$. The shorter line always was $1.0 \mathrm{in}$. above and flush with the longer line (see Fig. 1).

In Experiment 2, each $S$ saw 15 test stimuli. The objective combined lengths were $1.5,3.0$, and $6.0 \mathrm{in}$. for five test stimuli each. In each set of five, one test stimulus contained a single line, two contained two lines, and two contained four lines. Table 2 and Fig. 2 show the five different distributions of length used. On two- and four-line displays, lines were stacked $0.5 \mathrm{in}$. apart. The shorter line was below the longer line on half of the two-line displays.

In Experiment 3, the test stimuli corresponded exactly with those in Experiment 2, with the topmost line in a test stimulus in Experiment 2 becoming the leftmost line in the corresponding test stimulus in Experiment 3. In 
Table 1

Experiment 1: Apparent Combined Length, by Distribution of Objective Length Between Two Lines

\begin{tabular}{|c|c|c|c|c|c|c|}
\hline \multirow[b]{4}{*}{$\begin{array}{l}\text { Distribution } \\
\text { of Objective } \\
\text { Length }(\%)\end{array}$} & \multicolumn{5}{|c|}{ (Entries are in Inches) } & \\
\hline & \multicolumn{5}{|c|}{ Objective Combined Length (In.) } & \\
\hline & \multicolumn{2}{|c|}{1.5} & \multicolumn{2}{|c|}{3.0} & \multicolumn{2}{|c|}{6.0} \\
\hline & $\begin{array}{c}\text { Apparent } \\
\text { Combined } \\
\text { Length }\end{array}$ & $\begin{array}{l}\text { Change } \\
\text { Relative } \\
\text { to Single- } \\
\text { Line Match }\end{array}$ & $\begin{array}{c}\text { Apparent } \\
\text { Combined } \\
\text { Length }\end{array}$ & $\begin{array}{c}\text { Change } \\
\text { Relative } \\
\text { to Single- } \\
\text { Line Match }\end{array}$ & $\begin{array}{c}\text { Apparent } \\
\text { Combined } \\
\text { Length }\end{array}$ & $\begin{array}{c}\text { Change } \\
\text { Relative } \\
\text { to Single- } \\
\text { Line Match }\end{array}$ \\
\hline Single Line & 1.57 & -- & 3.16 & -- & 6.18 & -- \\
\hline $\begin{array}{l}\text { Two Lines } \\
5 / 95 \\
10 / 90 \\
15 / 85 \\
20 / 80 \\
25 / 75 \\
30 / 70 \\
35 / 65 \\
40 / 60 \\
45 / 55 \\
50 / 50\end{array}$ & $\begin{array}{l}1.76 \\
1.86 \\
1.81 \\
1.97 \\
1.97 \\
1.98 \\
2.08 \\
2.01 \\
1.97 \\
1.92\end{array}$ & $\begin{array}{r}+.19 \\
+.29 \\
+.24 \\
+.40 \\
+.40 \\
+.41 \\
+.51 \\
+.44 \\
+.40 \\
+.35\end{array}$ & $\begin{array}{l}3.34 \\
3.53 \\
3.49 \\
3.58 \\
3.70 \\
3.56 \\
3.61 \\
3.61 \\
3.43 \\
3.55\end{array}$ & $\begin{array}{r}+.18 \\
+.37 \\
+.33 \\
+.42 \\
+.54 \\
+.40 \\
+.45 \\
+.45 \\
+.27 \\
+.39\end{array}$ & $\begin{array}{l}6.36 \\
6.50 \\
6.28 \\
6.47 \\
6.55 \\
6.54 \\
6.18 \\
6.21 \\
6.17 \\
6.19\end{array}$ & $\begin{array}{r}+.18 \\
+.32 \\
+.10 \\
+.29 \\
+.37 \\
+.36 \\
.00 \\
+.03 \\
.01 \\
+.01\end{array}$ \\
\hline
\end{tabular}

Note-All lines were horizontal, with one placed 1.0 in. above the other in the two-line case. $N=20$

Table 2

Experiment 2: Apparent Combined Length, by Distribution of Objective Length Between Lines, and by Number of Lines (Entries are in Inches)

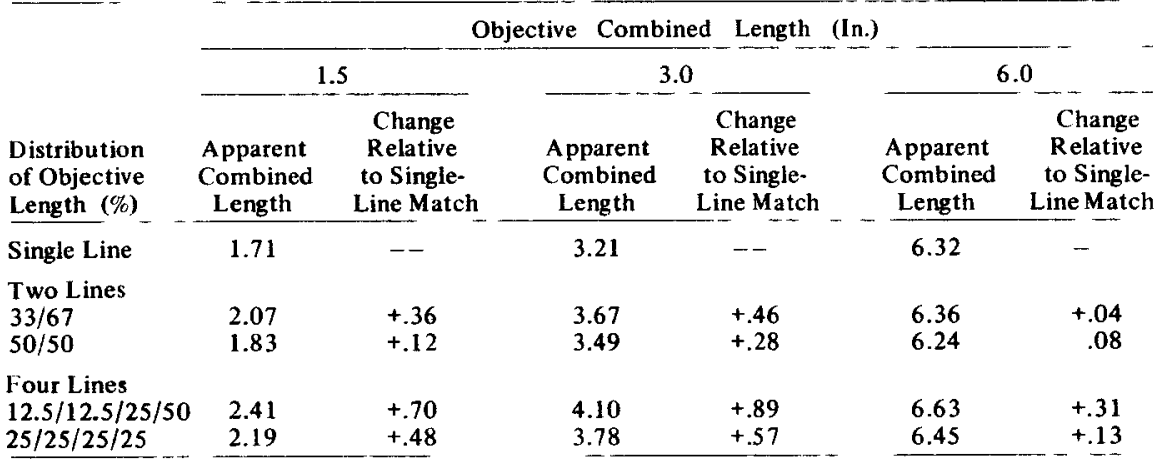

Note-All lines were horizontal, with 0.5 in. between adjacent lines in the two-and four-line stacks. $N=20$.

Experiment 3, lines were 1 in. apart, so that a 3.0 -in. four-line stimulus with three intervening 1 -in. gaps extended over a distance of 6 in. Ss were told to ignore the empty interval between line segments and to estimate only the combined length of the line segments themselves.

In Experiment 4, lines were stacked one above the other, as in Experiments 1 and 2, but the vertical separation between adjacent lines was varied, ranging from .125 in. to 2 in. (see Table 3 for further details). The distribution of objective length was $33 / 67$ for all two-line displays, on half of which the shorter line was above the longer one. The distribution was $12.5 / 12.5 / 25 / 50$ for all four-line stimuli. The order of the four lines in the stacks was varied randomly, except that no two $12.5 \%$ lines were next to each other. In all, there were 25 displays, of which 9 were 1.5 in. in objective length, 7 were 3.0 in., and 9 were $6.0 \mathrm{in}$. For half the Ss the lines were flush left, as in Experiments 1 and 2, and for half they were flush right (the stimulus sheet was rotated $180 \mathrm{deg}$ ). Placing the lines flush left or flush right made little difference, so data from the two conditions were combined.

Subjects. Twenty Harvard University students served as Ss in Experiment 1, 20 in Experiment 2, 10 in Experiment 3, and 20 in Experiment 4. Ss in Experiment 1 were paid.

Data analysis. The physical length of the one, two, or four lines in the test stimulus will be termed its "objective combined length"; the length to which $S$ sets the variable comparison line will be termed the "apparent combined length" of the test stimulus.

Results on the single-line condition $(0 / 100)$ revealed a consistent bias towards making the variable line longer: a 1.57 variable comparison line in Experiment 1 matched a 1.5-in. single-line test stimulus; a 3.16 in. matched a 3.0 ; and a 6.18 in. matched a 6.0 (see Table 1). A tendency to overestimate the test (standard) stimulus has been reported by other investigators (e.g., Piaget \& Lambercier, 1956; Gardner \& Long, 1960a,b; Rock \& Kaufman, 1962). To partial out this "error of the standard," the apparent combined length of a two- or four-line stimulus was evaluated relative to the apparent length of the single-line match. For example, for the 1.5 in., 5/95 two-line stimulus, apparent combined length was 1.76 in., which represents a +.19 -in. change relative to the 1.57-in. single-line match.

\section{Results and Discussion}

In Experiment 1, as Table 1 and Fig. 3 show, additivity did not hold: The apparent combined length for two lines was consistently larger, by up to about $1 / 2$ in. for all three objective lengths, than the single-line match. As Fig. 3 shows, the maximum increase of about $1 / 2$ in. occurred when the shorter of the two lines was one-fourth to one-third the objective length of the longer line (i.e., 25/75 to $35 / 65$ distribution of length). The tendency to overestimate two-line stimuli was quite consistent. For example, the increase in apparent combined length for the $5 / 95$ distribution, relative to the $0 / 100$

\section{Distribution of}

objective length

Test stimuli

between lines (\%)

$0 / 100$

\section{$35 / 65$}

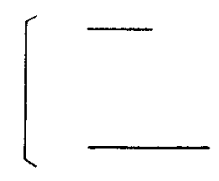

$50 / 50$

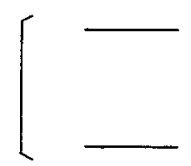

Fig. 1. Some test stimuli used in Experiment 1. (Shown, drawn to scale, are displays containing 1.5 -in. objective combined length, and having a 1.0 -in. interval between lines.) 
(single-line) case, was significant for the 1.5-in. objective length case (+.19 in., $t=3.11$, df $=19, \mathrm{p}<.01)$ and the 3.0-in. case ( +.18 in., $t=2.78$, $d f=19, p<.02)$, though not for the 6.0 -in. case $(+.18$ in., $t=1.25$, df $=19$, n.s.).

In an analysis of variance that excluded the single-line $(0 / 100)$ condition, the distribution of length between the two lines had a significant effect on apparent combined length $(F=2.90$, $\mathrm{df}=9 / 171$, $\mathrm{p}<.01$ ). As Fig. 3 shows, for all three objective lengths, apparent combined length increased and then decreased as the distribution of length was changed in $5 \%$ steps from $5 / 95$ to $50 / 50$. There was a significant interaction between distribution and objective combined length $(F=1.88$, $\mathrm{df}=18 / 342, \quad \mathrm{p}<.05)$, reflecting the tendency for the extent of overestimation to decline more rapidly, as the distribution neared the $50 / 50$ point, for 6.0 -in. than for 1.5- and 3.0-in. stimuli.

\section{Distribution of}

objective length

Test stimuli

between lines $(\%)$

$0 / 100$

$33 / 67$

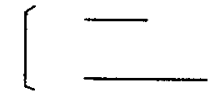

$50 / 50$

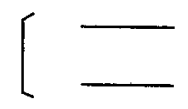

$12.5 / 12.5 / 25 / 50$

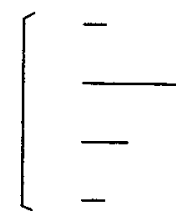

$25 / 25 / 25 / 25$

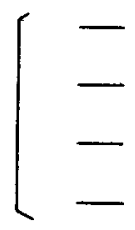

Fig. 2. Some test stimuli used in Experiment 2. (Shown, drawn to scale, are displays containing 1.5-in. objective combined length, and having an 0.5 -in. interval between adjacent lines.)

Table 3

Experiment 3: Apparent Combined Length, by Distribution of Objective Length Between Lines, and by Number of Lines (Entries are in Inches)

\begin{tabular}{|c|c|c|c|c|c|c|}
\hline \multirow[b]{3}{*}{$\begin{array}{l}\text { Distribution } \\
\text { of Objective } \\
\text { Length (\%) } \\
\end{array}$} & \multirow{2}{*}{\multicolumn{4}{|c|}{ Objective }} & \multirow{2}{*}{\multicolumn{2}{|c|}{ (In.) }} \\
\hline & & & & & & \\
\hline & $\begin{array}{c}\text { Apparent } \\
\text { Combined } \\
\text { Length } \\
\end{array}$ & $\begin{array}{c}\text { Change } \\
\text { Relative } \\
\text { to Single- } \\
\text { Line Match } \\
\end{array}$ & $\begin{array}{c}\text { Apparent } \\
\text { Combined } \\
\text { Length } \\
\end{array}$ & $\begin{array}{c}\text { Change } \\
\text { Relative } \\
\text { to Single- } \\
\text { Line Match } \\
\end{array}$ & $\begin{array}{c}\text { Apparent } \\
\text { Combined } \\
\text { Length }\end{array}$ & $\begin{array}{r}\text { Change } \\
\text { Relative } \\
\text { to Single- } \\
\text { Line Match } \\
\end{array}$ \\
\hline Single Line & 1.64 & -- & 3.09 & -- & 6.22 & -- \\
\hline $\begin{array}{l}\text { Two Lines } \\
33 / 67 \\
50 / 50\end{array}$ & $\begin{array}{l}2.00 \\
1.88\end{array}$ & $\begin{array}{l}+.36 \\
+.24\end{array}$ & $\begin{array}{l}3.56 \\
3.37\end{array}$ & $\begin{array}{r}+.47 \\
+.28\end{array}$ & $\begin{array}{l}6.46 \\
6.25\end{array}$ & $\begin{array}{l}+.24 \\
+.03\end{array}$ \\
\hline $\begin{array}{l}\text { Four Lines } \\
12.5 / 12.5 / 25 / 50 \\
25 / 25 / 25 / 25\end{array}$ & $\begin{array}{l}2.29 \\
2.07\end{array}$ & $\begin{array}{r}+.65 \\
+.43 \\
\end{array}$ & $\begin{array}{l}4.18 \\
4.05\end{array}$ & $\begin{array}{r}+1.09 \\
+.96\end{array}$ & $\begin{array}{l}6.88 \\
6.50\end{array}$ & $\begin{array}{l}+.66 \\
+.28\end{array}$ \\
\hline
\end{tabular}

Note-All lines were horizontal, and all were on the same horizontal level, with 1.0 in between lines. $N=10$

In Experiment 2, as Table 2 shows, apparent combined length was greater for four-line than for two-line displays, greater for displays with unequally long lines $(33 / 67$ and $12.5 / 12.5 / 25 / 50)$ than for those with equally long lines $(50 / 50$ and $25 / 25 / 25 / 25)$. With the single-line case excluded, number of lines (two vs four) had a significant effect on apparent combined length $(F=17.49, \mathrm{df}=1 / 19$, $\mathrm{p}<.001$ ), as did the distribution of length (equally vs unequally long) $(F=14.02$, $\mathrm{df}=1 / 19, \mathrm{p}<.001)$. No interaction term was significant. On two-line displays, apparent combined length was significantly greater for the 33/67 than for the 50/50 condition (.18 in., $t=3.23, \quad d f=19$, $\mathrm{p}<.01)$.

In Experiment 3, where lines were strung out horizontally, very nearly the same extent of overestimation occurred as in Experiment 2, as can be seen by comparing Tables 2 and 3 , which suggests that the basic factors producing the overestimation are not tied to a particular configuration of lines. In Experiment 3, for the condition producing the least effect (50/50, two lines), the overestimation, gauged relative to the single-line match, was significant in the 1.5 -in. case $(+.24$ in., $\mathrm{t}=2.80$, df $=9$, p $<.025)$ and in the 3.0 -in. case $(+.28$ in., $t=3.02, \quad d f=9$, $\mathrm{p}<.02$ ), though not in the 6.0-in. case ( +.03 in., $t=0.17, d f=9$, n.s.).

Further, as in Experiment 2, the overestimation in Experiment 3 was significantly greater for four-line than for two-line test stimuli $(F=9.42$, df $=1 / 9$, $p<.025)$ and for test stimuli in which the two or four lines were of unequal length $(F=11.29, \quad \mathrm{df}=1 / 9, \quad \mathrm{p}<.01)$. The interaction between number of lines and objective combined length also was significant $(\mathrm{F}=3.56, \mathrm{df}=2 / 18, \mathrm{p}<.05)$. On two-line displays, though, the greater overestimation for the $33 / 67$ (vs 50/50) case was only marginally significant (.18 in., $t=2.05, d f=9, p<.10$ ).

The greater overestimation of length for four-line (vs two-line) displays in Experiments 2 and 3 may be due not to number of lines but to confounded factors. Segments were shorter, on the average, in the four-line display than in the two-line display of the same objective combined length, and relative overestimation was greater for groups of shorter lines, as can be seen by comparing the 1.5- and 6.0-in. cases in Tables 2 and 3 . A second confounded factor, examined in

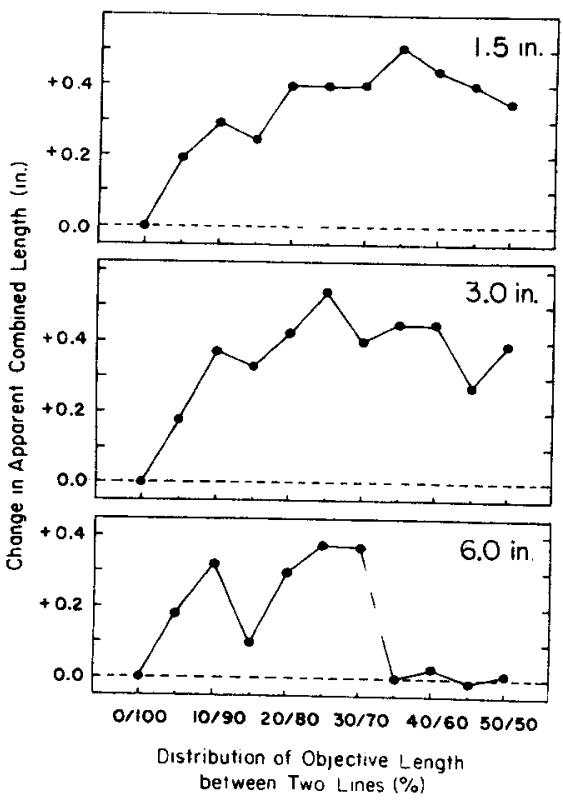

Fig. 3. Experiment 1: Change in apparent combined length, relative to single-line match, by distribution of objective length between the two lines. (Points lying above dashed lines indicate overestimation of the length in set of two lines. $N=20$.) 
Table 4

Experiment 4: Apparent Combined Length, by Size of (Vertical) Interval Between (Horizontal) Lines, and by Number of Lines (Entries are in Inches)

Objective Combined Length (In.)

\begin{tabular}{|c|c|c|c|c|c|c|}
\hline \multirow[b]{2}{*}{$\begin{array}{l}\text { Interval } \\
\text { Between } \\
\text { Lines (In.) }\end{array}$} & \multicolumn{2}{|c|}{1.5} & \multicolumn{2}{|c|}{3.0} & \multicolumn{2}{|c|}{6.0} \\
\hline & $\begin{array}{c}\text { Apparent } \\
\text { Combined } \\
\text { Length }\end{array}$ & $\begin{array}{l}\text { Change } \\
\text { Relative } \\
\text { to Single- } \\
\text { Line Match }\end{array}$ & $\begin{array}{c}\text { Apparent } \\
\text { Combined } \\
\text { Length }\end{array}$ & $\begin{array}{c}\text { Change } \\
\text { Relative } \\
\text { to Single- } \\
\text { Line Match }\end{array}$ & $\begin{array}{l}\text { Apparent } \\
\text { Combined } \\
\text { Length }\end{array}$ & $\begin{array}{c}\text { Change } \\
\text { Relative } \\
\text { to Single- } \\
\text { Line Match }\end{array}$ \\
\hline Single Line & 1.66 & -- & 3.20 & -- & 6.15 & -- \\
\hline $\begin{array}{l}\text { Two Lines } \\
.125 \\
.25 \\
.50 \\
1.00 \\
2.00\end{array}$ & $\begin{array}{l}1.87 \\
1.86 \\
1.89 \\
2.10 \\
---\end{array}$ & $\begin{array}{l}+.21 \\
+.20 \\
+.23 \\
+.44 \\
--\end{array}$ & $\begin{array}{l}\overline{-}- \\
3.38 \\
3.50 \\
3.70 \\
--\end{array}$ & $\begin{array}{l}-- \\
+.18 \\
+.30 \\
+.50 \\
--\end{array}$ & $\begin{array}{l}-\overline{6} \\
6.20 \\
6.44 \\
6.42 \\
6.43\end{array}$ & $\begin{array}{l}-- \\
+.05 \\
+.29 \\
+.27 \\
+.28\end{array}$ \\
\hline $\begin{array}{l}\text { Four Lines } \\
.125 \\
.25 \\
.50 \\
1.00 \\
2.00\end{array}$ & $\begin{array}{l}1.79 \\
1.98 \\
2.19 \\
2.18 \\
-\quad\end{array}$ & $\begin{array}{l}+.13 \\
+.32 \\
+.53 \\
+.52 \\
--\end{array}$ & $\begin{array}{c}- \\
3.45 \\
3.64 \\
3.95 \\
+\end{array}$ & $\begin{array}{l}-- \\
+.25 \\
+.44 \\
+.75 \\
--\end{array}$ & $\begin{array}{l}-\overline{6} \\
6.22 \\
6.35 \\
6.56 \\
6.57\end{array}$ & $\begin{array}{r}-- \\
+.07 \\
+.20 \\
+.41 \\
+.42\end{array}$ \\
\hline
\end{tabular}

Experiment 4, is the amount of space between lines. A stack or string of four lines is several times as high or long as a stack or string of two lines.

In Experiment 4, as Table 4 shows, the greater the vertical separation between lines in a stack, the greater the overestimation of the combined length. The amount of overestimation doubled, on the average, as the separation between adjacent lines increased from .25 in. to .50 in., increased by another $50 \%$ as the separation increased from .50 in. to $1.0 \mathrm{in.,}$ but did not change as the separation increased from $1.0 \mathrm{in}$. to $2.0 \mathrm{in}$.

The effect of vertical separation was analyzed both on the basis of relative separation (i.e., .125-in. separation for 1.5-in. objective length was regarded as equivalent to .25 -in. separation for 3.0-in.) and absolute separation. Relative separation on two- and four-line stimuli had a significant effect on apparent combined length $(F=9.53, \mathrm{df}=2 / 38$, $\mathrm{p}<.001)$, as did absolute separation $(F=10.46, \quad \mathrm{df}=2 / 38, \quad \mathrm{p}<.001)$. No interaction terms were significant. Apparent combined length was generally greater for four-line than for two-line stimuli, but the difference was not significant in either analysis of variance.

\section{EXPERIMENT 5}

In Experiment 5, $\mathrm{S}$ saw two pairs of lines simultaneously, both for either $1 \mathrm{sec}$ or $3 \mathrm{sec}$, and indicated which pair appeared to contain more total length. Both pairs in a given presentation were in the $25 / 75$ to $50 / 50$ range, and, for convenience, the one falling closer to $25 / 75$ will be called the unequally long pair. Sometimes pairs were doubled up so that each of the two sets contained four lines.
Unequally long pairs in the $25 / 75$ to $35 / 65$ range looked longer than $50 / 50$ pairs in Experiments 1, 2, and 3, and the strength of this illusion may depend on geometrical illusion for a longer duration or for a larger number of repeat exposures, the illusion typically diminishes (e.g., Lewis, 1912; Mountjoy, 1958; Schiller \& Wiener, 1962). Piaget, Bang, and Matalon (1958), for instance, found maximums for various illusions at tachistoscopic exposures ranging from 0.04 to $0.5 \mathrm{sec}$, with the most typical maximum occurring at $0.1 \mathrm{sec}$. In Experiments 1 to 4, where exposure duration was unlimited, several Ss reported becoming aware that they were overestimating the combined length of pairs of lines. In Experiment 5, the 1-sec exposure ought to be more effective than the 3-sec exposure in forcing $S$ to rely on his initial, naive impression and thus ought to produce a larger relative overestimation of the unequally long pair.

\section{Method}

Apparatus and procedure. $\mathrm{S}$ sat alone in a dark room, his head on a chin rest, 21 in. from a DEC Type 340 display scope (controlled by a PDP-4 computer) on which horizontal 0.03-in. thick lines were illuminated. A blue-pass filter counteracted a long-persistence yellow phosphorescence.

Two sets of lines were presented, one on the left side and one on the right side of the display scope, and $S$ was to indicate, after the exposure, which set looked longer. As in Experiments 1 to $4, S$ was told to adopt a global perceptual attitude and to respond according to how long the lines looked as a total, rather than how long they actually were. Individual lines varied from $1.0 \mathrm{in}$. to $3.1 \mathrm{in}$., so the most exposure duration. When $S$ views a disparate distribution of length was $25 / 75$ (when 1.0-in. and 3.1-in. lines were paired). In a given set, the pair lying closer to $25 / 75$ will be called "unequally long," and the other "equally long."

Each S received 264 trials, half at random with $1-\sec$ exposure and half with $3-\sec$ exposure. On half of the trials, sets of pairs were doubled up so that four lines were compared with four lines. The doubling up was done so that two unequally long pairs formed the four lines on one side and two equally long pairs formed the other four lines.

The lines in a pair or foursome were stacked in random order, with 0.5 in. between adjacent lines in pairs and 0.25 in. in the stacks of four lines. Lines on the left were flush right and were 1.0 in. away from lines on the right, which were flush left. The two groups of lines never had the same combined length. In $90 \%$ of the cases, the equally long pair or foursome was objectively longer.

Subjects. Twenty Harvard University students served as paid Ss.

\section{Results}

The unequally long set looked longer than the equally long set a higher proportion of the time for the $1-\sec$ than for the $3-\mathrm{sec}$ exposure (39\% vs $35 \%$ ), which was significant $(\mathrm{t}=3.33, \mathrm{df}=19$, $\mathrm{p}<.005)$. Thus, the shorter the exposure, the stronger the illusion, i.e., the greater the apparent combined length of pairs towards $25 / 75$ (vs 50/50).

\section{GENERAL DISCUSSION}

In the present study, apparent combined length did not equal, but exceeded, the sum of individual apparent lengths. Given a power function exponent of 1.0, for additivity to hold, two lines should look as long as the single line with the same objective length; yet Experiments 1 to 4 found that two lines look longer than the single line with the same length. The present results would be consistent with a power function exponent of less than 1.0. The results of partition scaling (e.g., category scales, bisection, equisection), in addition to being nonlinearly related to those of ratio scaling (Stevens, 1957), also underestimate the power function exponent (e.g., Stevens, 1955), which suggests that similar biases are operative in sum production, as used herein, and partition scaling. S. S. Stevens (personal communication) has said, in fact, that the present experiments in effect called for partitioning; $S$ was presented with several sections (partitions) and asked what the sections were partitions of. The convexity of the partition scale, with the parts adding to more than the whole, depends on the "noise," Stevens noted, so that when the 
judgment becomes easier, as with the $50 / 50$ pairs, the sum of the pairs declines.

The fact that amount of separation between lines affected apparent combined length (Experiment 4) suggests an additional factor. Filling a spatial (Lewis, 1912) or a temporal interval (Fraisse, 1963) with more stimuli, up to a certain point, makes the interval seem larger. Perhaps, as the present results suggest, the inverse holds as well, i.e., increasing the spatial or temporal interval makes the filled material seem larger or more numerous. Thus, the more area falling within a given radius of the lines, the greater the apparent combined length. Multiline sets, then, ought to look larger than single-line stimuli of the same objective length in part because they occupy or "control" more space, and such an effect ought to increase as the lines are moved further apart, which is precisely what was found in Experiment 4.

One limitation on the generality of the present results should be noted. Only a four-fold range of objective combined length was used ( $1.5 \mathrm{in}$. to $6.0 \mathrm{in}$.). Further, the overestimation of combined length inexplicably was generally greater for 1.5- and 3.0-in. stimuli than for 6.0-in. stimuli.

\section{REFERENCES}

DAWSON, W. E. An experimental analysis of judgments of sensory difference. Unpublished doctoral dissertation, Harvard University, 1968.

FRAISSE, P. The psychology of time. New York: Harper \& Row, 1963.

GARDNER, R. W., \& LONG, R. I. Errors of the standard and illusion effects with the inverted-T. Perceptual \& Motor Skills, 1960a, 10, 47-54.

GARDNER, R. W., \& LONG, R. I. Errors of the standard and illusion effects with $L$-shaped figures. Perceptual \& Motor Skills, 1960b, 10, 107-109.

GOUDE, G. On fundamental measurement in psychology. Stockholm: Almqvist \& Wiksell, 1962.

HUBEL, D. H., \& WIESEL, W. Receptive fields, binocular interaction and functional architecture in the cat's visual cortex. Journal of Physiology, 1962, 160, 106-154.

LETTVIN, J., MATURANA, H., PITTS, W., \& MCCULLOCH, W. Two remarks on the visual system of the frog. In W. A. Rosenblith (Ed.), Sensory communication. New York: Wiley, 1961. Pp. 757-777.

LEWIS, E. O. The illusion of filled and unfilled space. British Journal of Psychology, 1912, 5, 36-50.

MOUNTJOY, P. T. Effects of exposure time and intertrial interval upon the decrement to the Müller-Lyer illusion. Journal of Experimental Psychology, 1958, 56, 97-102.

PIAGET, J., BANG, V., \& MATALON, B. Note on the law of temporal maximum of some optico-geometric illusions. American Joumal of Psychology, 1958, 71, 277-282.

PIAGET, J.. \& LAMBERCIER, M. Grandeurs projectives et grandeurs réales avec étalon éloigné. Archives Psychologie (Geneva). 1956. $35,257-280$.

ROCK, I., \& KAUFMAN, L. The moon illusion,
II. Science, 1962, 136, 1023-1031.

SCHILLER, P., \& WIENER, M. Binocular and stereoscopic viewing of geometrical illusions. Perceptual \& Motor Skills, 1962, 15, 739-747. STEVENS, S. S. The measurement of loudness. Journal of the Acoustical Society of America, $1955,27,815-829$.

STEVENS, S. S. On the psychophysical law. Psychologicad Review, 1957, 64, 153-181.

STEVENS, S. S., \& GALANTER, E. H. Ratio scales and category scales for a dozen perceptual continua. Joumal of Experimental Psychology, 1957, 54, 341-377.

STEVENS, S. S., \& GUIRAO, M. Subjective scaling of length and area and the matching of length to loudness and brightness. Journal of Experimental Psychology, 1963, 66, 177-186.

TEGHTSOONIAN, M. The judgment of size. American Journal of Psychology, 1965, 78, 392-402.

TEGHTSOONIAN, M., \& TEGHTSOONIAN, R. Seen and feit length, Psychonomic Science, $1965,3,465-466$.

\section{NOTES}

1. This study was supported by a predoctoral traineeship by the U.S. Public Health Service, National Institute of General Medical Sciences, 5 T01 GM01011-07, to Harvard University. I would like to thank David V. Cross, Edwin B. Newman, William E. Dawson, S. S. Stevens, and Thomas G. R. Bower for their encouragement and helpful comments and suggestions.

2. Address: Department of Psychology, City College of CUNY, New York, N.Y. 10031.

(Accepted for publication December 15, 1969.) 